JRPB, Vol. 7, No. 1, Maret 2019, Hal. 1-7

DOI: $10.29303 /$ jrpb.v7i1.97

ISSN 2301-8119, e-ISSN 2443-1354

Tersedia online di http://jrpb.unram.ac.id/

\title{
LAJU DEOKSIGENASI DAN LAJU REAERASI SUNGAI BEDADUNG SEGMEN DESA ROWOTAMTU KECAMATAN RAMBIPUJI KABUPATEN JEMBER
}

\author{
Deoxygenation and Reaeration Rate of Bedadung River in Rowotamtu Village \\ Segment, Rambipuji Sub District, Jember Regency
}

Sri Wahyuningsih ${ }^{1, *)}$, Elida Novita ${ }^{1}$, Rahayu Ningtias ${ }^{1}$

${ }^{1}$ Teknik Pertanian, Fakultas Teknologi Pertanian, Universitas Jember

Email $^{*}$ : sriwahyuningsih.ftp@unej.ac.id.

Diterima: November 2018

Disetujui: Februari 2019

\begin{abstract}
Bedadung River in Rowotamtu Village segment is located in the middle of town closed to domestic area and agricultural area. Therefore, it has great benefits as a source of water to fulfill domestic needs and irrigation needs. Humans activities in using Bedadung River lead to changes in water quality. This research's aim was to determine the rate of deoxygenation and reaeration in the river. Dissolved oxygen values was determined by calculating the reaeration rate $(R)$ and deoxygenation rate $(K)$. The rate of deoxygenation was calculated using the equation of hydroscience, while the rate of reaeration was calculated using the equation of $O$ 'Connor and Dobbins. The research result showed the value of deoxygenation in Bedadung Rivers was $0.598 \mathrm{mg} / \mathrm{L}$ day and value of reaeration in Bedadung Rivers was $5.392 \mathrm{mg} / \mathrm{L}$ day.
\end{abstract}

Keywords: Bedadung River, deoxygenation rate, reaeration rate

\begin{abstract}
ABSTRAK
Sungai Bedadung segmen Desa Rowotamtu merupakan sungai dengan lokasi di tengah perkotaan yang dekat dengan pemukiman warga serta area pertanian, sehingga memiliki manfaat yang besar sebagai sumber air pemenuhan kebutuhan rumah tangga dan kebutuhan irigasi. Aktivitas manusia yang dilakukan dalam pemanfaatan Sungai Bedadung menyebabkan terjadinya perubahan kualitas air. Tujuan penelitian ini adalah untuk mengetahui laju deoksigenasi dan laju reaerasi pada Sungai Bedadung. Nilai oksigen terlarut dapat diketahui dengan menentukan laju reaerasi (R) dan laju deoksigenasi (D). Perhitungan laju deoksigenasi menggunakan persamaan Hydroscience. Sedangkan untuk menghitung laju reaerasi dihitung menggunakan persamaan O'cconor dan Dobbins. Hasil penelitian menunjukkan nilai rata-rata laju deoksigenasi pada Sungai Bedadung sebesar 0,598 mg/L.hari dan nilai rata-rata laju reaerasi sebesar 5,392 $\mathrm{mg} / \mathrm{L}$ hari.
\end{abstract}


Kata kunci: laju deoksigenasi, laju reaerasi, Sungai Bedadung,

\section{PENDAHULUAN}

\section{Latar Belakang}

Air merupakan komponen yang berperan penting dalam kelangsungan hidup manusia dan makhluk hidup lainnya, Salah satu sumber air yang paling banyak dimanfaatkan adalah air sungai. Wilayah Kabupaten Jember memiliki beberapa sungai besar, salah satunya adalah Sungai Bedadung yang alirannya melewati Desa Rowotamtu. Lokasi sungai yang berada ditengah perkotaan dekat dengan pemukiman warga dan area pertanian memiliki manfaat bagi masyarakat yang tinggal di sekitar alirannya. Saluran drainase yang berada sebelum titik lokasi penelitian membawa limbah pertanian dan limbah domestik yang alirannya langsung masuk ke sungai. Sedangkan di titik terakhir lokasi penelitian dibatasi oleh DAM Bedadung yang membendung aliran sungai.

Berbagai aktivitas manusia dalam memenuhi kebutuhan hidup yang berasal dari kegiatan rumah tangga dan pertanian juga akan menghasilkan limbah yang memberi sumbangan pada penurunan kualitas air sungai (Suriawiria, 2003). Oksigen Terlarut (Dissolved Oxygen, DO) memiliki peranan penting bagi sungai sebagai indikator penentuan kualitas air di sungai tersebut. Perubahan DO digunakan untuk menggambarkan kemampuan sungai dalam membersihkan diri (self purification). Perubahan konsentrasi DO pada perairan dipengaruhi oleh proses pengurangan oksigen terlarut (deoksigenasi) akibat aktivitas bakteri dalam menguraikan bahan organik dalam air (dekomposisi bahan organik) serta proses peningkatan oksigen terlarut (reaerasi) yang disebabkan oleh turbulensi aliran sungai (Arbie, dkk.,
2015). Oleh sebab itu, perlu adanya analisis laju deoksigenasi dan laju reaerasi Sungai Bedadung guna mengetahui seberapa besar kemampuan sungai untuk memulihkan diri.

\section{Tujuan}

Tujuan dari penelitian ini adalah menentukan laju deoksigenasi dan laju reaerasi Sungai Bedadung segmen Desa Rowotamtu.

\section{METODE PENELITIAN}

\section{Alat dan Bahan}

Alat yang digunakan meliputi GPS, pasak, roll meter, tali tampar, 1 set current meter, termometer, botol sampel, cold box, kamera, botol Winkler $250 \mathrm{ml}$, erlenmeyer $1000 \mathrm{ml}$, pipet volumetrik 100 $\mathrm{ml}$, pipet suntik $1 \mathrm{ml}$, buret $25 \mathrm{ml}$, bola penghisap, corong, desikator, oven, kertas saring diameter $0,45 \mu \mathrm{m}$, cawan, timbangan analitis, $\mathrm{pH}$ meter, dan turbidimeter. Bahan yang digunakan meliputi sampel air Sungai Bedadung, MnSO4, Alkali-iodida Azida, $\mathrm{H}_{2} \mathrm{SO}_{4}$ 0,1 $\mathrm{N}$, Amilum, $\mathrm{Na}_{2} \mathrm{~S}_{2} \mathrm{O}_{3} \quad 0,025 \mathrm{~N}$, dan Aquades.

\section{Metode}

Analisis kualitas air

Analisis kualitas air digunakan untuk mengetahui kelas air sebagai tolak ukur mutu air berdasarkan Permen RI Nomor 82 tahun 2001 dengan parameter DO dan BOD. Analisa DO dilakukan dengan titrasi Winkler dan analisa $\mathrm{BOD}_{5}$ dilakukan pada temperatur inkubasi $20^{\circ} \mathrm{C}$ selama lima hari. Pengambilan sampel menggunakan metode grab (sesaat) secara langsung di badan sungai untuk menunjukkan karakteristik sampel air saat pengambilan. Pengambilan sampel dilakukan di empat titik lokasi seperti yang disajikan pada Gambar 1 . 


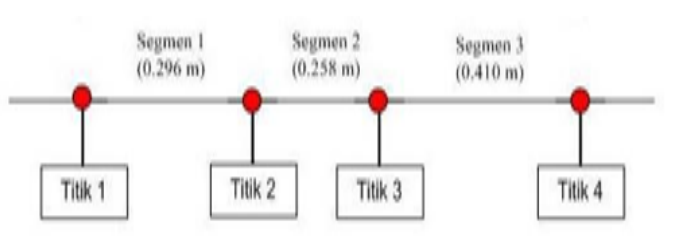

Gambar 1. Titik lokasi penelitian

\section{Analisis debit Sungai Bedadung}

Pengukuran debit dilakukan dengan menghitung luas penampang profil sungai (cross section) dan mengukur kecepatan aliran menggunakan current meter. Debit sungai dihitung menggunakan persamaan berikut.

$Q=A \times V$

Dimana:

$\mathrm{Q}=$ Debit aliran $\left(\mathrm{m}^{3} /\right.$ detik)

$\mathrm{A}=$ Luas Penampang $\left(\mathrm{m}^{3}\right)$

$\mathrm{V}=\operatorname{Kecepatan}(\mathrm{m} /$ detik$)$

\section{Perhitungan nilai $K^{\prime}$ dan BOD ultimat
Nilai $\mathrm{K}^{\prime}$ adalah konstanta} dekomposisi bahan organik (hari ${ }^{-1}$ ) pada botol BOD dengan inkubasi pada temperatur $20^{\circ} \mathrm{C}$ Penentuan nilai $\mathrm{K}$ ' dengan metode Thomas, menggunakan data pengamatan BOD 10 hari (Keputusan Menteri Negara Lingkungan Hidup Nomor 110 Tahun 2003). Persamaan yang digunakan sebaai berikut (Metcalf dan Eddy, 2004).

n.a + b. $\sum y-\sum y^{\prime}=0$, dan

a. $\sum y+$ b. $\sum y^{2}-\sum y^{\prime}=0$

Dimana:

$\mathrm{N}=$ jumlah data

$\mathrm{K}^{\prime}=-\mathrm{b}$

$\mathrm{Y}=$ hasil pengukuran BOD

$y^{\prime}=\frac{y_{n+1}-y_{n-1}}{2 \Delta t}$,

$\mathrm{a}=-\mathrm{b}$ UBOD

Model ini menyatakan bahwa laju oksidasi biokimiawi senyawa organik ditentukan oleh konsentrasi senyawa organik sisa (residual). Jika konsentrasi awal senyawa organik sebagai BOD adalah Lo yang dinyatakan sebagai BOD ultimat dan Lt adalah BOD pada saat $\mathrm{t}$, maka persamaan dinyatakan sebagai berikut.

$\mathrm{Lt}=\operatorname{Lo.e}\left(\mathrm{K}^{\prime} . \mathrm{t}\right)$

Dimana:

$\mathrm{t}=$ waktu

$\mathrm{K}=$ konsentrasi reaksi orde satu $\left(\right.$ hari $\left.^{-1}\right)$

$\mathrm{Lt}=$ konsentrasi organik saat $\mathrm{t}$

$\mathrm{L}_{0}=$ konsentrasi secara keseluruhan

Perhitungan Konstanta Deoksigenasi $\underline{\left(K_{d}\right) \text { dan Laju Deoksigenasi }\left(r_{D}\right)}$

Menurut Haider (2013), konstanta dekomposisi bahan organik pada perairan berbeda dengan konstanta dekomposisi bahan organik pada botol BOD. Kedalaman sungai mempengaruhi kehidupan mikroba karena suplai oksigen terlarut (Yustiani, dkk., 2008). Berdasarkan hal tersebut, penentuan konstanta deoksigenasi (Kd) menggunakan persamaan Hydroscience sebagai berikut.

$\mathrm{K}_{\mathrm{D}}=0,3(\mathrm{H} / 8)^{-0,434}$

Dimana:

$\mathrm{K}_{\mathrm{D}}=$ konstanta deoksigenasi $\left(\right.$ hari $\left.^{-1}\right)$

$\mathrm{H}=$ kedalaman $(\mathrm{m})$

Laju deoksigenasi adalah kecepatan penurunan konsentrasi oksigen yang terlarut di dalam air karena telah digunakan oleh bakteri aerob untuk menguraikan zat- zat organik yang dapat menurunkan kualitas air sungai (Razif, 1994). Laju deoksigenasi dinyatakan dengan persamaan sebagai berikut.

$r_{D}=-K^{\prime} \cdot L^{-K t}$

Dimana:

$\mathrm{K}^{\prime}=$ konstanta deoksigenasi $\left(\right.$ hari $\left.^{-1}\right)$;

$\mathrm{r}_{\mathrm{D}}=$ laju deoksigenasi $\left(\mathrm{mg} / \mathrm{L}\right.$ hari $\left.^{-1}\right)$.

Lo $=$ BOD ultimat pada titik pencampuran $(\mathrm{mg} / \mathrm{l})$ 
Perhitungan konstanta reaerasi $\left(K_{r}\right)$ dan laju reaerasi $\left(r_{R}\right)$

Nilai konstanta kecepatan reaerasi $\left(\mathrm{K}_{\mathrm{R}}\right)$ menunjukkan besarnya laju penyerapan oksigen atmosfer ke dalam perairan. Dari rumus O'Connor-Dobbins besarnya $K_{R}$ di perairan tergantung dari kombinasi antara nilai kecepatan $(\mathrm{V})$ dan kedalaman air $(\mathrm{H})$ (Astono, 2010). Nilai konstanta reaerasi menggunakan persamaan O'Connor dan Dobbins sebagai berikut.

$$
\mathrm{K}_{2}^{\prime}=\frac{294\left(\mathrm{D}_{\mathrm{LT}} . \mathrm{U}\right)^{1 / 2}}{\mathrm{H}^{3 / 2}}
$$

Dimana:

$\mathrm{D}_{\mathrm{LT}}=$ koefisien difusi molekular untuk oksigen $\left(\mathrm{m}^{2} /\right.$ hari $)$;

$\mathrm{U}=$ kecepatan aliran rata-rata (m/detik);

$\mathrm{H}=$ kedalaman aliran rata-rata $(\mathrm{m})$

Laju reaerasi menunjukkan kecepatan peningkatan nilai oksigen yang terlarut di dalam air karena turbulensi aliran sungai (Astono, 2010). Peralihan oksigen ini dinyatakan dengan persamaan sebagai berikut.

$\mathrm{r}_{\mathrm{R}}=\mathrm{K}^{\prime} 2(\mathrm{D})$

Dimana:

$\mathrm{r}_{\mathrm{R}}=$ laju reareasi $\left(\mathrm{mg} / \mathrm{L}\right.$ hari $\left.^{-1}\right)$;

$\mathrm{K}^{\prime} 2$ = Konstanta reareasi $\left(\right.$ hari $\left.^{-1}\right)$;

$\mathrm{D}=$ Konsentrasi oksigen terlarut jenuh $(\mathrm{mg} / \mathrm{L})$ - konsentrasi oksigen terlarut $(\mathrm{mg} / \mathrm{L})$

\section{HASIL DAN PEMBAHASAN}

\section{Kualitas Air Sungai Bedadung}

Data hasil analisa kualitas air Sungai Bedadung segmen Desa Rowotamtu disajikan pada tabel 1. Nilai DO pada Sungai Bedadung segmen Desa Rowotamtu masih memenuhi kriteria mutu air kelas II menurut pada Peraturan Pemerintah RI No 82 tahun 2001. Berdasarkan tabel 1, nilai DO terendah pada titik lokasi 1. Saluran drainase sebelum titik lokasi 1 membawa limbah yang langsung masuk ke Sungai Bedadung.

Kadar DO semakin menurun seiring dengan semakin meningkatnya limbah organik di perairan tersebut. Hal ini disebabkan oksigen yang dibutuhkan oleh bakteri untuk menguraikan zat organik semakin banyak (Simanjuntak, 2007). Sedangkan nilai DO tertinggi pada titik lokasi 2 dipengaruhi oleh dasar sungai didominasi oleh kerikil dan memiliki nilai kecepatan arus tertinggi dari titik lokasi penelitian lainnya. Sebagaimana penyataan Fisesa, dkk., (2014), bahwa tingginya nilai DO di sungai disebabkan oleh kecepatan arus sehingga proses aerasi meningkat.

Tabel 1. Kualitas air Sungai Bedadung

\begin{tabular}{|c|c|c|c|c|c|}
\hline \multirow{2}{*}{$\begin{array}{l}\text { Para- } \\
\text { meter } \\
(\mathrm{mg} / \mathrm{L})\end{array}$} & \multicolumn{4}{|c|}{ Titik Pengambilan } & \multirow{2}{*}{$\begin{array}{c}\text { Mutu } \\
\text { Air } \\
\text { Kelas } \\
\text { II }\end{array}$} \\
\hline & $\mathrm{T} 1$ & $\mathrm{~T} 2$ & T3 & $\mathrm{T} 4$ & \\
\hline DO & 6,36 & 7,35 & 7,14 & 6,73 & 4 \\
\hline BOD & 1,69 & 1,47 & 1,69 & 1,75 & 3 \\
\hline
\end{tabular}

Sumber: ${ }^{*}$ Peraturan Pemerintah Nomor 82 Tahun 2001

Nilai BOD pada Sungai Bedadung masih memenuhi kriteria mutu air kelas II menurut Peraturan Pemerintah RI No 82 tahun 2001. Berdasarkan tabel 1, nilai BOD tertinggi pada titik lokasi 4 disebabkan oleh masuknya bahan organik yang berasal limbah yang terakumulasi dari titik lokasi sebelumya dan mengendap pada titik lokasi 4. Waktu pengabilan sampel pada masa peralihan musim menyebabkan debit aliran sungai kecil sehingga terbendung tidak dapat mengalir melewati bangunan mercu DAM Bedadung. Sedangkan kecepatan aliran tertinggi dan rata-rata kedalaman terendah pada titik lokasi 2 membuat proses penyebaran oksigen terlarut merata dan penguraian bahan organik berlangsung dengan baik sehingga memiliki nilai BOD terendah. 


\section{Debit Sungai Bedadung}

Data hasil pengukuran dan perhitungan debit ditunjukkan tabel 2 .

Tabel 2. Debit Sungai Bedadung

\begin{tabular}{cccc}
\hline $\begin{array}{c}\text { Titik } \\
\begin{array}{c}\text { Peng } \\
\text { ambil } \\
\text { an }\end{array}\end{array}$ & $\begin{array}{c}\text { Penampang } \\
\left(\mathrm{m}^{2}\right)\end{array}$ & $\begin{array}{c}\text { Kec } \\
\text { Rata- } \\
\text { rata } \\
(\mathrm{m} / \\
\text { detik })\end{array}$ & $\begin{array}{c}\text { Debit } \\
\left(\mathrm{m}^{3} /\right. \\
\text { detik })\end{array}$ \\
\hline 1 & 25,20 & 0,55 & 11,23 \\
2 & 20,85 & 0,72 & 12,66 \\
3 & 37,25 & 0,45 & 10,52 \\
4 & 28,22 & 0,18 & 4,98 \\
\hline
\end{tabular}

Berdasarkan tabel 2 diketahui tingginya nilai debit pada titik lokasi 2 dipengaruhi oleh nilai kecepatan aliran yang memiliki nilai tertinggi pada titik lokasi tersebut yaitu sebesar 0,72 $\mathrm{m} / \mathrm{detik}^{2}$, disebabkan oleh profil sungai yang menurun berdasarkan hasil pengukuran long section. Sedangkan titik lokasi 4 menunjukkan nilai debit yang terendah karena nilai kecepatan aliran pada titik tersebut merupakan yang terendah diantara titik lokasi lainnya yaitu sebesar $0,18 \mathrm{~m} / \mathrm{detik}^{2}$. Sifat aliran Sungai Bedadung yang merupakan sungai intermittent (periodik) menyebabkan debit aliran Sungai Bedadung menurun secara keseluruhan saat peralihan musim. Debit Sungai Bedadung yang kecil menyebabkan aliran pada titik lokasi 4 terbendung karena tidak dapat melewati bangunan mercu DAM Bedadung. Kondisi tersebut menghambat aliran sungai sehingga nilai kecepatan aliran pada titik lokasi 4 menjadi yang terendah.

\section{Nilai K dan BOD Ultimate}

Dari hasil perhitungan, nilai $\mathrm{K}^{\prime}$ sebesar 0,309 Hari $^{-1}$. K' merupakan nilai yang menunjukkan besarnya kecepatan pemakaian oksigen. Nilai BOD Ultimate ditunjukkan pada tabel 3 berikut.
Tabel 3. Nilai BOD ultimate

\begin{tabular}{cc}
\hline $\begin{array}{c}\text { Titik } \\
\text { Pengambilan }\end{array}$ & $\begin{array}{c}\text { BOD Ultimate (Lo) } \\
\mathrm{mg} / 1\end{array}$ \\
\hline 1 & 2,14 \\
2 & 1,86 \\
3 & 2,14 \\
4 & 2,21 \\
\hline
\end{tabular}

BOD ultimate adalah jumlah total oksigen yang dikonsumsi selama reaksi (Astuti dan Niken, 2015). BOD ultimate memliki nilai yang hampir sama karena jenis bahan pencemar yang masuk di keempat titik merupakan jenis perncemar yang sama yaitu dari limbah pertanian dan limbah domestik. Semakin besar nilai BOD maka semakin kecil ketersediaan oksigen terlarut dalam air (Ayudina, 2017).

\section{Deoksigenasi dan reaerasi}

Hasil perhitungan $\mathrm{K}_{\mathrm{D}}, \mathrm{K}_{\mathrm{R}}$, $\mathrm{rD}$, dan rR disajikan pada tabel berikut.

Tabel 4. Nilai $K_{D}, K_{R}, r_{D}$, dan $r_{R}$

\begin{tabular}{cccc}
\hline Titik & $\mathrm{K}_{\mathrm{D}}$ & $\mathrm{K}_{\mathrm{R}}$ & $\mathrm{Lt}$ \\
Pengambilan & Hari-1 & Hari-1 & $\mathrm{mg} / 1$ \\
\hline 1 & 1,357 & 8,598 & 0,457 \\
2 & 1,572 & 12,301 & 0,396 \\
3 & 1,207 & 3,921 & 0,455 \\
4 & 1,276 & 2,944 & 0,472 \\
\hline & & & \\
\hline Titik & $\mathrm{D}$ & $\mathrm{rD}$ & $\mathrm{rR}$ \\
& & & \\
Pengambilan & $\mathrm{mg} / \mathrm{l}$ & $\mathrm{mg} / \mathrm{l} . \mathrm{hari}$ & $\mathrm{mg} / \mathrm{l} . \mathrm{hari}$ \\
\hline 1 & 1,565 & 0,62 & 13,454 \\
2 & 0,284 & 0,622 & 3,499 \\
4 & 0,506 & 0,55 & 1,986 \\
& 0,893 & 0,602 & 2,629 \\
\hline
\end{tabular}

Konstanta deoksigenasi $\left(\mathrm{K}_{\mathrm{D}}\right)$ tertinggi pada titik lokasi 2 disebabkan oleh rata-rata kedalam yang memiliki nilai terendah dari titik lokasi lainnya. Sedangkan nilai $K_{D}$ terendah pada titik lokasi 3 dipengaruhi profil sungai yang 
dalam dibandingkan titik lokasi lainnya. Semakin dalam kedalaman suatu sungai maka akan semakin sedikit kandungan oksigennya dan sedikit juga jumlah mikroorgansime yang dapat hidup di perairan tersebut sehingga mempengaruhi nilai $\mathrm{K}_{\mathrm{D}}$ (Ayudina, 2017). Konstanta reaerasi $\left(K_{R}\right)$ di perairan tergantung dari kombinasi antara nilai $\mathrm{V}$ dan $\mathrm{H}$. Jadi semakin deras dan dangkal suatu perairan semakin besar angka $\mathrm{K}_{\mathrm{R}}$ dan sebaliknya (Astono, 2010). Nilai $K_{R}$ tertinggi pada titik 2 dipengarui kecepatan aliran yang tinggi dan rata-rata kedalaman yang rendah. Sedangkan $K_{R}$ terendah berada pada titik lokasi 4 dipengaruhi oleh kondisi sungai yang lebih dalam dan tenang. Perbandingan antara nilai kecepatan yang rendah dan profil sungai yang dalam menyebabkan nilai konstanta reaerasi menurun.

Nilai laju deoksigenasi tertinggi pada titik lokasi 2 dipengaruhi oleh konstanta deoksigenasi yang memiliki nilai tertinggi yaitu $1,572 \mathrm{mg} / \mathrm{L} / \mathrm{hari}$. Sedangkan nilai laju deoksigenasi terendah pada titik lokasi 3 dipengaruhi oleh konstanta deoksigenasi yang memiliki nilai terendah sebesar 1,207 $\mathrm{mg} / \mathrm{L} /$ hari. Nilai laju reaerasi tertinggi pada titik lokasi 1 dan terendah pada titik 3 dipengarui oleh nilai $K_{R}$. Selain $K_{R}$, nilai defisit oksigen (D) juga mempengaruhi tinggi rendahnya nilai laju reaerasi. Tingginya nilai $D$ disebabkan oleh selisih oksigen saturasi dengan oksigen aktual. Selisih tersebut disebabkan oleh limbah bahan organik yang mencemari sungai menghasilkan nilai DO aktual yang berbeda dari DO saturasi yang didapatkan dari nilai suhu air sungai.

\section{KESIMPULAN DAN SARAN}

\section{Kesimpulan}

Dari hasil penelitian Sungai Bedadung di segmen Desa Rowotamtu memiliki rata-rata laju deoksigenasi sebesar 0,598 mg/L.hari dan laju reaearsi sebesar 5,392 mg/L.hari. Nilai laju deoksigenasi yang lebih kecil dari nilai laju reaerasi. Sungai Bedadung segmen Desa Rowoamtu memiliki kemampuan dalam proses permurnian alami.

\section{Saran}

Penentuan konstanta reaksi bahan organik (K') dihitung di setiap titik. Pencemaran non-point source memungkinkan terdapat perbedaan nilai konstanta reaksi bahan organik di masing-masing titik sesuai dengan bahan pencemar yang masuk.

\section{UCAPAN TERIMAKASIH}

Terima kasih kami sampaikan kepada pihak-pihak yang terlibat dalam penelitian ini. Terima kasih kepada Dr. Sri Wahyuningsih, S.P., M.T. dan Dr. Elida Novita, S.TP., M.T. atas waktu, pikiran dan perhatian dalam penelitian ini.

\section{DAFTAR PUSTAKA}

Metcalf dan Eddy. (2004). Wastewater Engineering, $4^{\text {th }}$ edition. McGraw-Hill, New York.

Arbie, R.R., Nugraha, W.D., dan Sudarno. (2015). Studi Kemampuan Self Purification pada Sungai Progo Ditinjau dari Parameter Organik DO Dan BOD, Jurnal Teknik Lingkungan, Volume 4(3).

Astono, W. (2010). Penetapan Nilai Konstanta Dekomposisi Organik (Kd) Dan Nilai Konstanta Reaerasi (Ka) Pada Sungai Ciliwung Hulu - Hilir. Jurnal EKOSAINS. Volume 2(1), 40-45

Astuti, P., dan Niken, T.M. Pratiwi. (2015). Evaluasi Metode Penentuan Parameter Biochemical Oxygen Demand (Bod) Lismining. Jurnal LIMNOTEK Perairan Darat Tropis di Indonesia Volume 23(1). 44-49.

Ayudina, A. (2017). Penentuan Nilai Koefisien Laju Deoksigenasi Sungai Citarum Segmen Tengah, Jurusan 
Teknik Lingkungan, Fakultas Teknik, Universitas Pasundan. Diakses dari http://repository.unpas.ac.id/27824/ 1/ABSTRAK.docx.

Fisesa, D.E., Setyobudiandi, I., dan Krisanti, M. (2014). Kondisi perairan dan struktur komunitas makrozoobentos di Sungai Belumai Kabupaten Deli Serdang Provinsi Sumatera Utara. Jurnal Depik. Volume 3 (1), 1-9

Haider, H., Ali, W., dan Haydar, S. (2013). A Riview of Dissolved Oxygen and Biochemical Oxygen Demand models for Large rivers. Pakistan journal of Engineering and Applied Science Volume 12, 127-142.

Razif, M. (1994). Penentuan Konstanta Laju Kecepatan Deoksigenasi, Reaerasi dan Sedimentasi di Sepanjang Sungai dengan Simulasi Komputer. Jurnal IPTEK ITS Volume 5(1), 79-90.

Simanjuntak, M. (2007). Oksigen Terlarut dan Apparent Oxygen Utilization di Perairan Teluk Klabat, Pulau Bangka.
Jurnal Ilmu kelautan. Volume 12(2), 59-66.

Suriawiria, U. (2003). Mikrobiologi Air dan Dasar-Dasar Pengolahan Buangan Secara Biologis. Bandung: Alumni.

Yustiani, Y.M., Wahyuni, S., dan Alfian, M.R. (2018). Investigation on the Deoxygenation rate of water of Cimanuk River indramayu Indonesia. Rasayan J. Chem Volume 11(2), 475481.

Kementrian Lingkungan Hidup. (2003). Keputusan Menteri Negara Lingkungan Hidup Nomor 110 tentang Pedoman Penetapan Daya Tampung Beban Pencemaran Air pada Sumber Air, Jakarta.

Kementrian Lingkungan Hidup. (2001). Pemerintah Republik Indonesia Nomor 82 tentang Pengelolaan Kualitas Air dan Pengendalian Pencemaran Air, Jakarta, Kementrian Lingkungan Hidup. 